Disponível em:

http://editora.unoesc.edu.br/index.php/race

Race, Joaçaba, v. 15, n. 1, p. 349-374, jan./abr. 2016

\title{
COMPETÊNCIAS GERENCIAIS EVIDENCIADAS E DESEJADAS DOS INTEGRANTES DO FÓRUM DE GESTÃO DE PESSOAS DA REDE FEDERAL DE EDUÇAÇÃO PROFISSIONAL, CIENTÍFICA E TECNOLÓGÍCA
}

\author{
Evidenced managerial competences and desired of the members of Forum of People \\ Management of Federal Network of Vocational, Scientific and Technological Education
}

Simone P. T. de Mello

E-mail: sptmello@gmail.com Doutora em Educação pela Universidade Federal do Rio Grande do Sul; Pós-doutoranda em Administração no Programa de Pós-graduação em Administração da Universidade Federal de Santa Catarina; Professora adjunta e Vice-Diretora da Faculdade de Administração e Turismo da Universidade Federal de Pelotas. Endereço para correspondência: Rua General Osório, 725, Centro, 96020-000, Pelotas, Rio Grande do Sul, Brasil.

Pedro Antônio de Melo

E-mail: pedro.inpeau@gmail.com

Pós-doutor em Educação Superior pelo Instituto Internacional para a Educação Superior na América Latina e o Caribe (IESALC) da Unesco; Doutor Honoris Causa pela Honorable Academia Mundial de Educación HAME; Professor da Universidade Federal de Santa Catarina.

Raul Teixeira de Mello Filho E-mail: raulfilho@ifsul.edu.br Mestre em Educação pela Universidade Federal de Pelotas; Especialista em Recursos Humanos pela Universidade Federal de Santa Catarina.

Artigo recebido em 03 de abril de 2015. Aceito em 14 de dezembro de 2015. 
Resumo

A Política para o Desenvolvimento de Pessoal da administração pública federal via Decreto Federal (DF) n. 5.707/06 tem como uma de suas diretrizes a promoção da capacitação gerencial do servidor e sua qualificação para o exercício de atividades de direção e assessoramento, tendo como um dos instrumentos dessa política a gestão por competências. Com este estudo se objetivou identificar os desafios cotidianos, os entendimentos sobre gestão por competências, assim como mapear as competências gerenciais dos integrantes do Fórum de Gestão de Pessoas (Forgep) da Rede Federal de Educação Profissional, Científica e Tecnológica (Rfept), no caso, gestores de pessoas que participam de encontros regulares do citado Fórum. A metodologia é de essência qualitativa. Utilizou-se o software limesurvey para a coleta de dados e, para a análise destes, valeu-se da análise de conteúdo (BARDIN, 2009; VERGARA, 2006). Os resultados revelam os desafios mais frequentes dos gestores: excesso de trabalho e carência de servidores. Seus entendimentos sobre gestão por competências são vagos se comparados à literatura pertinente. Suas competências mais evidenciadas são: comunicação, liderança e gestão de conflitos, e as desejadas por eles são: organização do tempo, comunicação, motivação e liderança. Espera-se que a pesquisa contribua para ações de governo mais efetivas. É essencial conceber o gerenciamento de pessoas como área estratégica das instituições, o que implica capacitação e qualificação de gestores de pessoas, sujeitos significativos no desenvolvimento da gestão por competências na prática.

Palavras-chave: Competências gerenciais. Mapeamento de competências. Gestão de pessoas. Administração pública.

\section{Evidenced and desired managerial competences of the members of Forum of People Management of Federal Network of Vocational, Scientific and Technological Education}

Abstract

The Policy for Staff Development of the Federal Government via Federal Decree (DF) n. 5,707/06 has as one of its guidelines promoting managerial capacity of the servers and their qualification for the exercise of direction and advisory activities, with the management by competencies as one of the instruments that policy. This study aimed to identify the daily challenges, the understandings about management by competencies, as well as to map the managerial competencies of the members of People Management Forum (Forgep) of the Federal Professional Education Network, Science and Technology (Rfept), in this case, people managers participate of regular meetings of that forum. The methodology has qualitative essence. We used the limesurvey software for data collection, and for data analysis, it was used the content analysis (BARDIN, 2009; VERGARA, 2006). The results show the managers' most frequent challenges: overwork and lack of employees. Their comprehension about management by competencies are vague when compared to the literature. Their most evident competencies 
are: communication, leadership, and conflict management, and those desired by them are: organization of working time, communication, motivation, and leadership. It is essential to conceive people management as a strategic area of the institutions, which implies in training and qualification of people managers, significant subjects in the management by competencies development in practice.

Keywords: Management competencies. Mapping of competencies. People management. Public administration.

\section{INTRODUÇÃO}

Diversas mudanças no mundo do trabalho foram acompanhadas por alterações na administração das organizações. Flexibilidade, resultados, aprendizagem e competências passam a fazer parte de um cenário que exige mudanças nas práticas organizacionais, revelando que muitas das pressões no setor privado acontecem também no público, as quais incidem tanto nas pessoas quanto nos processos.

No Brasil, a evolução da área de gestão de pessoas acompanhou as distintas formas de administrar os negócios. Conforme Costin (2010), no âmbito público, a administração do Estado brasileiro se originou com uma concepção patrimonialista, centralizadora, marcada pelo clientelismo, passando depois para uma administração burocrática, impessoal, regulatória, carente de inovação e criatividade, e, num formato mais recente, avançou para um modelo gerencial, com foco nos resultados, menos centralizadora e hierárquica.

Da monarquia à república atual, as mudanças no gerenciamento de pessoas na administração pública brasileira acompanharam as formas de administrar, sejam estas mais centralizadoras sejam mais autônomas, mas o desenvolvimento da área ainda parece caminhar a passos lentos. Uma justificativa talvez seja de que a área em muitas organizações não assume uma posição estratégica, mas, sim, operacional.

Levantamento recente sobre Governança e gestão de pessoas em 330 unidades da administração pública federal, realizado pelo Tribunal de Contas da União, detectou que, embora as atividades típicas de departamento de pessoal pareçam bem administradas, os indicadores revelam um nível rudimentar de desenvolvimento da gestão estratégica. Nesse relatório, conclui-se que as possíveis causas dessa condição precária são: a governança ruim, a escassez de profissionais com competências necessárias nas unidades de gestão de pessoas e a rigidez da legislação de pessoal (TRIBUNAL DE CONTAS DA UNIÃO, 2013).

O levantamento também revela um distanciamento entre a gestão de pessoas e a gestão estratégica nessas unidades investigadas. Logo, observa-se a necessidade 
de um modelo de gestão de pessoas que migre do controle das relações entre pessoas e organização (FLEURY; FISCHER, 1992) para alternativas mais autônomas, com responsabilidade e entrega, alinhando os objetivos individuais aos organizacionais (DUTRA, 2004; FLEURY; FLEURY, 2008).

Porém, observam-se esforços governamentais para o desenvolvimento da gestão de pessoas, a exemplo da Política e das Diretrizes para o Desenvolvimento de Pessoal da administração pública federal direta, autárquica e fundacional (PNPD), instituída a partir do Decreto Federal n. 5.707/2006. Uma das finalidades da política é adequar as competências requeridas dos servidores aos objetivos das instituições, vislumbrando, então, maior aderência entre o desenvolvimento de pessoas e a estratégia organizacional.

Então, a gestão por competências permeia esse cenário de mudanças na área de gestão de pessoas. De atribuições descritas em cargos e funções, com foco na função, a gestão por competências centra-se no desempenho dos trabalhadores, na ação, naquilo que pode ser efetivamente observado, evidenciado, e não mais na relação das tarefas inerentes ao cargo.

Todavia, ainda há escassez de publicações de caráter instrumental, considerando-se que grande parte das publicações sobre competências privilegia a realização de discussões conceituais sobre a noção do tema e proposições teóricas.

Assim, com este estudo se objetivou identificar os desafios relacionados à prática cotidiana dos entrevistados como gestores de pessoas no seu contexto de trabalho e os entendimentos destes sobre gestão por competências, assim como mapear as competências gerenciais dos integrantes do Fórum de Gestão de Pessoas (Forgep) da Rede Federal de Educação Profissional, Científica e Tecnológica (Rfept), no caso, gestores de pessoas que participam de encontros regulares do citado Fórum.

\section{METODOLOGIA}

Este estudo teórico-empírico compreendeu uma pesquisa exploratória, de orientação qualitativa, com o intuito de conhecer significados diante de uma dada realidade, que é o gerenciamento de pessoas na RFEPT. Buscou-se conhecer as competências gerenciais reveladas e desejadas a partir dos 155 gestores de pessoas do Forgep, órgão de assessoramento, consulta e deliberação do Conselho Nacional das Instituições (Conif), ao qual as instituições da RFEPT fazem parte.

Ainda, procurou-se investigar o que pensam os gestores participantes do Forgep considerando-se o papel destes no Fórum na atuação junto aos órgãos que elabo- 
ram as políticas de recursos humanos para o conjunto das instituições que compõem a RFEPT.

Os contatos iniciais com o Forgep indicaram 155 participantes, mas esse contingente não representava 155 dirigentes máximos da área de gestão de pessoas das instituições da EFEPT, a qual é composta por 64 instituições: 38 Institutos Federais de Educação, Ciência e Tecnologia, 23 Escolas Técnicas vinculadas a Universidades Federais, dois Centros Federais de Educação Tecnológica e uma Universidade Tecnológica.

Em geral, cada instituição tem mais de um servidor cadastrado no Fórum que detém cargo de direção na área de gestão de pessoas, mas que nem sempre é o dirigente máximo de gestão de pessoas da instituição. Contudo, participa, eventualmente, das reuniões do Fórum.

Optou-se por enviar o questionário aos 155 gestores do Forgep, respeitando a participação de todos os gestores. O documento foi composto por nove questões acessadas por meio do link gerado pelo limesurvey, software que permite aos usuários criarem rapidamente inquéritos on-line, trabalhando como um guia para autorrespondentes participarem de pesquisas, na versão 1.91. Esse link foi acessado por meio de e-mail enviado aos gestores.

Durante um mês, o instrumento ficou disponível. O questionário via limesurvey também tem a vantagem de ser respondido aos poucos, e esta foi uma das opções por se tratarem de perguntas abertas, assim como pela ciência da expressiva carga de trabalho diário desses dirigentes, o que, muitas vezes, inviabiliza-os de responderem a uma pesquisa com a tranquilidade desejada.

Decorridos 30 dias, observaram-se 29 respondentes. Após, mudou-se a estratégia, contatando-se o Forgep e aplicando-se os questionários impressos em uma das reuniões ordinárias do Fórum, obtendo-se, das 35 instituições representadas, 16 respondentes. Logo, 29\% dos integrantes do Forgep responderam ao questionário, totalizando 45 servidores, que são gestores de pessoal nas diversas áreas que compõem a gestão de pessoas. Logo, 29 gestores responderam ao questionário on-line e 16 responderam ao questionário impresso.

Esse percentual indica um retorno abaixo do esperado. Em um primeiro momento, pareceu que o contato virtual prejudicou o retorno do instrumento, mas quando da aplicação presencial, percebeu-se 45\% de não respostas, o que evidencia que parte dos gestores não participou da pesquisa, embora todos tenham tomado ciência dela.

As nove questões que compõem o questionário tratam dos seguintes temas: sexo, idade (em anos completos), tempo de exercício da função gerencial atual na Instituição (em anos completos), número de pessoas que gerencia atualmente, princi- 
pais desafios que enfrenta em seu cotidiano de trabalho, o que entende por gestão por competências e se está em andamento em sua instituição, descrição de uma ou mais competências gerenciais que possui e descrição de uma ou mais competências gerenciais que deseja adquirir ou melhorar. Tais categorizações foram elaboradas de forma interpretativa a partir de estudos sobre o tema.

A análise das respostas se ancora em Bardin (2009), e a análise de conteúdo, a posteriori, revelou os temas recorrentes nos discursos, assim como o que foi tratado sobre estes (VERGARA, 2006).

Enquanto limitações, observa-se que para subsidiar a adequada descrição da competência existem técnicas e métodos, como: análise documental, entrevista, grupo focal, questionário e observação (BRASIL, 2013).

Mas, diante de restrições para visitar todas as instituições da RFEPT, este estudo se valeu de questionários individuais via internet, inicialmente, e presenciais, poteriormente, assim como da análise documental nos sítios das instituições da RFEPT.

\section{REFERENCIAL TEÓRICO}

\subsection{O DESENVOLVIMENTO DA REDE FEDERAL DE EDUCAÇÃO PROFISSIONAL, CIENTÍFICA E TECNOLÓGICA}

A história da Rede Federal de Educação Profissional, Científica e Tecnológica (RFEPT) remonta o ano 1909, quando o então presidente da República, Nilo Peçanha, criou 19 escolas de Aprendizes e Artífices que, posteriormente, originaram os centros federais de educação profissional e tecnológica, os chamados CEFETs e, mais recentemente, os institutos federais de educação tecnológica, os IFETs (MELLO, 2007).

Na primeira república, a função inicial das escolas era atender aos “[...] filhos dos desfavorecidos da fortuna”, como consta no próprio Decreto Federal n. 7.566, de 23 de setembro de 1909. Segundo a autora, outro fato que foi emblemático na implantação da educação profissional foi o momento vivido pelo País marcado por profundas mudanças socioeconômicas, em virtude dos processos acelerados de industrialização e urbanização nas primeiras décadas do século XX (MELLO, 2007).

Tida no seu início como instrumento de política voltado para as classes menos privilegiadas social e economicamente, a RFEPT se configura, hoje, como importante estrutura para que todas as pessoas tenham efetivo acesso às conquistas científicas e tecnológicas. Mas foi a partir da década de 1980, diante de um novo cenário econômico e produtivo, que essas instituições cresceram e se estabeleceram com o desenvolvimento de novas tecnologias, agregadas à produção e à prestação de serviços. 
De lá para cá, a fim de atender à demanda educacional crescente, as instituições de educação profissional vêm buscando diversificar programas e cursos para elevar os níveis da qualidade da oferta. Cobrindo o território nacional, a rede federal tem dado continuidade à sua missão de qualificar profissionais para os diversos setores da economia brasileira, realizando pesquisa e desenvolvendo novos processos, produtos e serviços em colaboração com o setor produtivo, além disso, oferece cursos técnicos, superiores de tecnologia, licenciaturas, mestrados e doutorados (CONSELHO NACIONAL DAS INSTITUIÇÕES DA REDE FEDERAL DE EDUCAÇÃO PROFISSIONAL, CIENTÍFICA E TECNOLÓGICA, 2013).

A RFEPT vive a maior expansão de sua história. De 1909 a 2002, foram construídas 140 escolas técnicas no País. Entre 2003 e 2010, o Ministério da Educação entregou à sociedade 214 novas instituições previstas no plano de expansão da RFEPT. O MEC está investindo mais de R \$ 1,1 bilhão na expansão da educação profissional e tecnológica. O mapa da RFEPT revela que existem 354 unidades e mais de $400 \mathrm{mil}$ vagas para alunos em todo o País, com previsão de expansão para . 562 unidades, irão gerar cerca de 600 mil vagas (CONIF, 2013).

Atualmente, a RFEPT compreende Institutos Federais de Educação, Ciência e Tecnologia, Centros Federais de Educação Tecnológica, Escolas Técnicas vinculadas às Universidades Federais e a Universidade Tecnológica Federal, situada no Estado do Paraná.Ao todo, são 314 unidades vinculadas à RFEPT. Todavia, convém esclarecer que um Instituto Federal, pode ter cinco campi. Estes são considerados no computo geral como Unidades. Logo, as 314 são Unidades, distribuídas entre 38 Institutos, 23 Escolas Técnicas, dois Centros e uma Universidade Tecnológica (HELMANN, 2015).

\subsection{MAPEAMENTO DE COMPETÊNCIAS}

O mapeamento de competências é considerado uma etapa preliminar da gestão por competências. Para compreendê-lo, é necessário esclarecer, inicialmente, a gestão por competências, que é recente na administração pública brasileira.

O destaque a essa abordagem de gestão ocorreu, com mais ênfase, após a publicação do Decreto Federal n. 5.707/2006, que instituiu a política e as diretrizes para o desenvolvimento de pessoal da administração pública federal direta, autárquica e fundacional, entre outros aspectos.

O tema é complexo, na medida em que rompe com o desempenho no trabalho centrado na tarefa e passa a focar no indivíduo, em um primeiro momento. Parte-se do entendimento que conhecimentos e habilidades decorrentes do saber fazer já não 
são suficientes. Outros elementos passam a vigorar no contexto do trabalho, como as atitudes (ANTONELLO et al., 2010).

No setor público, a complexidade parece ser maior diante das legislações pertinentes ao setor, que limitam, em parte, a implantação da gestão por competências. No entanto, essa abordagem da gestão de pessoas possui uma série de etapas, procedimentos e metodologias.

Tendo como referências Le Boterf (1999) e Carbone et al. (2009), Brandão et al. (2012) utiliza a denominação gestão por competências, argumentando que a partícula “por”, quando utilizada na formação de adjuntos, indica intenção, propósito, desejo. Logo, a expressão anuncia a ideia de que o esforço gerencial tem como objetivo estimular, fomentar, desenvolver e mobilizar competências. Para esse autor, a gestão por competências vale-se de diferentes estratégias e instrumentos, com o propósito de identificar e desenvolver as competências necessárias à consecução dos objetivos organizacionais.

A definição de Fernandes (2013) apresenta a gestão por competências enquanto um modelo de gestão definido, descrito e formalizado, que compreende um conjunto de conceitos e práticas para desenvolver, de forma consistente, as competências das pessoas e da organização. Surge enquanto uma abordagem inovadora de gestão de pessoas, incorporando o tema do setor privado para o público, indicando uma relação mais harmônica com a estratégia, configurando o que Fernandes (2013) chama de gestão estratégica de pessoas com foco em competências.

No treinamento e desenvolvimento, a gestão por competências fornece à organização subsídios para estruturar programas de treinamento formais ou informais, a fim de desenvolver nas pessoas as competências necessárias (FERNANDES, 2013).

Logo, a gestão por competências atribui-se a organizações que deliberam e institucionalizam um conjunto de competências que desejam de seus colaboradores e as utilizam sistematicamente como parâmetro para trabalhar seus colaboradores (FERNANDES, 2013).

No âmbito da administração pública brasileira, a gestão por competência é conceituada no Decreto Federal n. 5.707/2006 como a gestão da capacitação orientada para o desenvolvimento do conjunto de conhecimentos, habilidades e atitudes necessárias ao desempenho das funções dos servidores, visando ao alcance dos objetivos da instituição.

Ao admitir essa configuração conceitual, Bergue (2014, p. 263) esclarece que no contexto da administração pública conhecimentos são “[...] aqueles elementos conceituais ou técnicos que uma pessoa detém ou precisa ter para o exercício de 
determinada atividade.” Habilidades aludem à “[...] capacidade de transformação do conhecimento em ação.” A comunicação, a capacidade analítica, a flexibilidade e a capacidade de persuasão são exemplos de habilidades. Já as atitudes estão relacionadas aos atributos de personalidade e postura pessoal e profissional. Estas revelam o "impulso do agente para a ação", e exemplos dessas atitudes são: valores éticos, transparência, franqueza, cortesia, cordialidade, respeito, entre outros.

O mapeamento de competências é considerado uma etapa preliminar da gestão por competências. Nem sempre se dispensa a devida atenção para esse processo significativo da abordagem, mas, como salienta Brandão (2012), grande parte das dúvidas, dificuldades, equívocos e imprecisões no desenvolvimento da gestão por competências emergem em processos de mapeamento destas.

Conceitualmente, o mapeamento de competências é o diagnóstico de competências, o qual visa identificar a discrepância entre as competências necessárias para concretizar a estratégia organizacional e as competências internas existentes na organização. Logo, o mapeamento se traduz em reconhecer o gap, a lacuna de competências (BRANDÃO, 2012).

Para tanto, aplicam-se métodos, técnicas e instrumentos para a realização dessa etapa de conhecimento das competências, assim como a sintonia entre estas.

Identificar competências individuais em uma organização, por exemplo, é uma fase do mapeamento de competências. Sua descrição operacional é parte desse processo instrumental que tem o objetivo de qualificar a ação ou a atuação do indivíduo no contexto de trabalho. Um caminho frequente tem sido descrever as competências em padrões de desempenho que refletem as expectativas da organização no que se refere ao desempenho de seus colaboradores (BRANDÃO, 2012).

De modo geral, a literatura orienta descrever desempenhos objetivos por meio de sentenças, as quais iniciam com um verbo seguido de um objeto de ação e uma condição descrita que pode ser acrescentada de um critério. Não é algo fácil de elaborar, mas o desenvolvimento da habilidade prática é importante na descrição das competências. Exemplo de sentença é "Redigir documentos, observando as normas de redação da presidência da república, sem erros ortográficos.”

Mas, para subsidiar a adequada descrição da competência, existem técnicas e métodos que também devem ser considerados, como: análise documental, entrevista, grupo focal, questionário e observação.

\subsection{DESENVOLVIMENTO GERENCIAL}


O desenvolvimento gerencial está associado às iniciativas de apoio das organizações ao crescimento tanto pessoal quanto profissional daqueles que detêm cargos de liderança nos diversos níveis das organizações.

Conforme Donadão (2013), os tópicos que se destacam quanto ao desenvolvimento gerencial atual dizem respeito à necessidade de alternativas inovadoras e com múltiplos formatos de desenvolvimento gerencial, muito além das salas de aula e videoconferências. Além disso, o desenvolvimento passa a ter uma importância estratégica, fazendo parte da agenda dos dirigentes.

Os tradicionais treinamentos já não se mostram eficazes diante da complexidade das relações intra e extra-organizacionais. De um conhecimento técnico e de uma liderança centralizadora, pautada no controle, o contexto do desenvolvimento gerencial atual tem levado os líderes a novos desafios.

Os atributos essenciais de desenvolvimento gerencial são a credibilidade e a confiança. O primeiro está associado ao sentir-se seguro e sólido em sua performance, com domínio de seu campo de trabalho. Já o poder de inspirar confiança está relacionado a atitudes, à coerência entre discurso e prática, a senso de justiça, desde julgar situações polêmicas e chegar a soluções justas para cada problema (DONADÃO, 2013).

Associadas aos desafios, a ambiguidade e a complexidade são dificuldades que revelam incertezas e aspectos ao gerenciar processos e pessoas. O papel do desenvolvimento gerencial na preparação do gestor pressupõe iniciativas de educação gerencial formal e informal que, muitas vezes, provocam mudanças no estilo, prática e comportamento das lideranças nos ambientes organizacionais (DONADÃO, 2013).

Borges-Andrade, Abbad e Mourão (2006), ao tratarem da competência técnica e política do profissional de treinamento, desenvolvimento e educação (TD\&E), argumentam que a justificativa das mazelas enfrentadas por estes profissionais está no próprio contexto de trabalho destes ou na (falta de) formação apropriada.

Para ele, as funções inerentes à gestão de pessoas são diferentes entre si, no que se refere à natureza de tarefas nelas realizadas e no que diz respeito aos conhecimentos exigidos de quem as executa. Nas funções de cargos, salários e controle, cadastro e pagamento predominam tarefas com rotinas padronizadas e regulatórias, com estrito cumprimento de normas e leis. Os conhecimentos exigidos estão ligados à administração de pessoal e à legislação trabalhista (BORGES-ANDRADE; ABBAD; MOURÃO, 2006).

No âmbito da seleção, as habilidades demandadas são inerentes às áreas de mensuração do comportamento e psicometria. Em razão da complexidade e hetero- 
geneidade dos conhecimentos e habilidades de outras funções de gestão de pessoas, como o TD\&E, é comum encontrar nessa área psicólogos, pedagogos, administradores e, em menor número, sociólogos, engenheiros e profissionais de letras e informática (BORGES-ANDRADE; ABBAD; MOURÃO, 2006).

Nas organizações contemporâneas a função gerencial de TD\&E tem se empoderado. A tecnologia e a mão de obra de baixo custo já não são diferenciais de sucesso nas organizações. Os indivíduos e suas competências aparecem como diferenciais estratégicos, e a valorização do chamado capital intelectual tem tomado grande importância no contexto organizacional.

No âmbito público no Brasil isso é visível. As referências usadas pela Escola Nacional de Administração Pública (ENAP) são oportunas e abrangentes. A escola coordena as escolas de governo da União e integra o Comitê Gestor da Política Nacional de Desenvolvimento de Pessoal, conforme discriminado no Decreto Federal n. 5.707/2006. Ainda, desenvolve o Programa de Gestão de Pessoas que objetiva contribuir para o desenvolvimento permanente do servidor público a partir da priorização de competências para a melhoria da eficiência, eficácia e qualidade dos serviços públicos prestados aos cidadãos.

Em um dos blocos desse programa, a escola promove a capacitação gerencial, fomentando o desempenho do gerente na gestão do desenvolvimento da equipe, assim como relacionando a gerência com os seus desafios no contexto da administração pública atual.

Esse desempenho desejado aos gerentes prevê comportamentos essenciais na relação gerente-equipe com base na concepção canadense de gerenciamento, que são: estabelecer uma relação positiva com seus servidores; criar um clima de confiança, comprometimento, respeito e empowerment; dar feedback positivo; dar feedback corretivo; conduzir entrevistas de Coaching e adotar uma abordagem de Coaching adequada à situação e ao contexto dos seus servidores (ESCOLA NACIONAL DE ADMINISTRAÇÃO PÚBLICA, 2012).

Para Bergue (2014, p. 66), a gestão de pessoas no setor público é complexa, tanto quanto seu desenvolvimento. A visão funcional da gestão de pessoas com formato departamental não condiz com a realidade atual na qual há demandas crescentes em complexidade, qualidade e quantidade. Tal diferenciação de demandas “[...] passa a exigir atuação compatível das pessoas em termos de desenvolvimento e mobilização de competências.”

Assim, a sociedade está a exigir um modelo de desenvolvimento gerencial menos prescritivo, funcional e centralizado no poder e no controle, em conhecimentos 
e em habilidades. Logo, as demandas recaem por um desenho gerencial mais atitudinal, mais participativo e integrador com o foco no cidadão.

\subsection{COMPETÊNCIAS GERENCIAIS}

Pode-se inferir que o desenvolvimento de competências permite resolver problemas de forma satisfatória em um contexto específico, mobilizando inúmeras capacidades de maneira integrada. Diversos autores destacam a articulação entre trabalhadores, organizações e sociedade, questões que permeiam o campo das competências (ANTONELLO, 2004; ZARIFIAN, 1999; LE BOTERF, 2002).

Mas tanto é importante definir competências quanto compreender seu desenvolvimento. Competência se evidencia por uma ação. Esse agir está vinculado a uma situação profissional e imerso a um contexto. Emergem junto às competências três categorias preliminares que as constituem: conhecimentos, habilidades e atitudes, unânimes nas referências sobre o tema.

Mas há outros aspectos inerentes ao tema. Antonello e Pantoja (2010) destacam o valor, a interação e a prática. Fleury e Fleury (2008) destacam que as competências agregam valor social ao indivíduo e valor econômico à organização, anunciando o autodesenvolvimento como relevante ao indivíduo, diante de uma situação profissional cada vez mais mutável e complexa.

Competências são cambiantes. Decorrem do pensar e agir em um dado contexto organizacional. Para Le Boterf (2002), competência é ação e se refere ao sujeito que assume responsabilidades diante de situações de trabalho. Ou seja, resulta do saber agir, querer agir e poder agir.

Então, competência pode ser considerada uma capacidade mobilizada, integrada e apreendida, que leva a um desempenho desejado. Sua mobilização depende de uma cultura organizacional que favoreça as condições para agir.

Quando se trata de competências diretivas das lideranças, observa-se que estas estão associadas às competências empresariais (organizacionais e essenciais). As competências de liderança incidem diretamente na análise de ações estratégicas. Conforme Fleury e Fleury (2008), estas são úteis para se compreender que as competências de liderança envolvem a relação do indivíduo com toda a empresa, em uma perspectiva sistêmica, que são:

a) competências de negócios: relacionadas à compreensão dos negócios, seus objetivos na relação com o mercado, clientes e competidores, ambiente político e social; 
b) competências técnico-profissionais: específicas para certa operação, ocupação ou atividade - produção, comercialização, produtos, finanças;

c) competências sociais: competências para interagir com as pessoas, comunicação, negociação, mobilização para mudanças, sensibilidade, cultura, trabalho em equipes, etc.

Por outro lado, Brandão (2012), ao tratar da escala de ordenação de competências gerenciais, a fim de verificar o grau de importância destas para os gerentes, apresenta sete competências que podem, ou não, ser relevantes ao desempenho de funções gerenciais. São as seguintes:

1) Formular planos e estratégias para cumprir as metas de sua equipe, estabelecendo ações, responsabilidades, prazos e prioridades.

2) Distribuir adequadamente as tarefas entre os integrantes de sua equipe, de acordo com as capacidades e aptidões de cada um.

3) Organizar as atividades de sua equipe, para realizá-las, no prazo previsto.

4) Comunicar-se com os integrantes de sua equipe, de forma transparente, mantendo-os permanentemente informados sobre questões importantes da empresa.

5) Gerenciar conflitos no ambiente de trabalho, procurando manter a coesão e a harmonia entre os integrantes de sua equipe.

6) Tomar decisões no trabalho, considerando os possíveis impactos sobre os empregados, o meio ambiente e a sociedade.

7) Estimular a participação dos empregados na tomada de decisões, valorizando as contribuições oferecidas por eles.

Brandão et al. (2010) desenvolveram uma escala para avaliar competências gerenciais, identificando as relevantes ao desempenho de gestores de uma instituição financeira, no caso, o Banco do Brasil. Ao final, revelaram 31 competências gerenciais, agrupadas em seis fatores denominados: estratégia e operações, resultado econômico, clientes, comportamento organizacional, processos internos e sociedade.

Maximiano (2004, p. 41-42) relaciona as competências necessárias aos ocupantes de cargos de nível gerencial, em que a habilidade conceitual - categoria intelectual, a capacidade de motivar e de liderar equipe - categoria interpessoal e conhecimento sobre a atividade - categoria técnica, são complementadas pela categoria intrapessoal. Essa última categoria é o que Henry Mintzberg chama de introspecção. 
O autor compreende todas as relações e formas de reflexão e ação da pessoa a respeito de si mesma como: “[...] autoanálise, autocontrole, automotivação, autoconhecimento, capacidade de organização pessoal e administração do próprio tempo.” (MAXIMIANO, 2004, p. 41-42).

Assim, há várias concepções em se tratando da abrangência das competências gerenciais, ora focando nos processos, ora focando nas pessoas, bem como no contexto intra e extra-organizacional. Os resultados a seguir visam triangular a informação fornecida pelos dirigentes de pessoas com o referencial anteriomente exposto.

\section{RESULTADOS}

O universo investigado totalizou 155 gestores de pessoas que fazem parte do Forgep, vinculado ao Conif. Destes, 29\% retornaram, totalizando 45 respondentes, conforme explicado na seção Metodologia.

Dos respondentes, 16 são homens e 29 são mulheres, respectivamente 35,6\% e 64,4\%. Observa-se predominância do gênero feminino em cargos de gestão de pessoas da Rede, o que reflete o aumento da participação da mulher em cargos gerenciais no mercado de trabalho não somente no setor privado, mas também no público.

A idade mínima observada foi 23 anos, e a máxima foi 64. A média de idade entre eles é 37, um público jovem em idade e também com pouco tempo de serviço na instituição. O tempo de exercício na função gerencial atual na instituição vai de menos de um ano (40\%) a dez anos. Esses 40\% equivalem a 18 servidores.

Em média, gerenciam 33 servidores. Há gestores com até 440 servidores subordinados. O fato pode ser explicado pela estrutura organizacional dessas instituições, que não é homogênea.

\subsection{DESAFIOS COTIDIANOS}

Quando questionados sobre seus desafios cotidianos, a intenção era de que respondentes identificassem situações que testam suas competências diariamente. As respostas revelam uma conta que não fecha: a ]a. Dois dos entrevistados justificam que a remuneração é baixa. Isso infere rotatividade, o que leva os servidores a se prepararem para outros concursos públicos, especialmente aqueles que ingressaram na carreira recentemente. Um dos gestores que evidencia o desafio "rotatividade” alega inclusive que “[...] há dificuldade de capacitação devido à rotatividade do setor.” (GP23, informação verbal).

A postura das pessoas em relação ao seu desenvolvimento profissional vem se transformando ao longo dos anos. No setor público isso é visível. A volatilidade 
relatada pelos gestores por parte de seus colaboradores, revelada na palavra "rotatividade", confirma esse novo contexto de um servidor em constante desenvolvimento, preparando-se para concursos, pouco interessado em se manter no mesmo cargo ao longo dos anos.

Atualmente, há 22.265 servidores técnicos-administrativos apenas nos institutos federais. A RFEPT passa por um processo de expansão significativo, com ampliação de matrículas, cursos, campus, infraestrutura, além de servidores docentes e técnicos-administrativos. Tal expansão acontece, de modo geral, em toda a administração pública federal brasileira (BRASIL, 2014).

Além disso, 15\% dos gestores de pessoas mencionaram a “capacitação” em seus desafios cotidianos, no entanto, não explicaram se é liberação para capacitação dos colaboradores, se trata-se de escassez de recursos para capacitação ou se falta capacitação para sua equipe ou para ele próprio enquanto gestor.

Contudo, vive-se um paradoxo na administração pública. Por um lado, o setor busca modernização, educação corporativa, o que implica organizações com estruturas e organização mais participativas em relação aos seus servidores, que privilegiem a autonomia e a criatividade. Por outro, as características estruturais da administração pública burocrática brasileira, permeada pela regulação e controle, como explicado por Borba in Mello (2012) inibem posturas mais flexíveis e participativas e acabam por limitar laços de comprometimento entre servidores e instituição. E isso é visível no turnover relatado pelos gestores. O dilema está em harmonizar interesses pessoais e organizacionais.

Outro desafio listado por 24\% dos respondentes é o "excesso de atividades". Alega-se grande fluxo de processos, excesso de rotinas administrativas, sobrecarga de trabalho, o que leva à exaustão e ao estresse. A regulação da administração pública explica, em parte, essa rotina desgastante na medida em que auditorias são frequentes no setor, demandam tempo e organização no que se refere às informações.

Entretanto, o excesso de atividades pode estar associado ao insipiente mapeamento de processos que aperfeiçoe o trabalho diário. O que leva, muitas vezes, os gestores a "apagar incêndios” diariamente. Um dos respondentes, ao descrever os desafios, argumenta que os “[...] processos não são padronizados e muitas vezes quando são disparados geram processos paralelos.”(GP07, informação verbal).

Além disso, há situações em que servidor removido ou redistribuído leva consigo a expertise no trato de algum assunto ou procedimento, levando tempo considerável para que seu substituto desenvolva o trabalho como o anterior o fazia. Logo, 
em se tratando de gestão de pessoas, nos aspectos legislação e desenvolvimento, por exemplo, leva-se tempo, talvez anos, para capacitar um servidor nessas áreas.

Paludo (2013) explica que por meio da gestão de processos é possível corrigir falhas e otimizar o desempenho da gestão. Para o autor, gerenciar processos implica planejar, monitorar, avaliar e revisar os processos organizacionais, procurando melhorá-los continuamente a fim de que os objetivos a eles vinculados possam ser alcançados de forma satisfatória e no tempo estabelecido.

Em uma dimensão menos operacional, 15\% dos gestores de pessoal mencionaram que há pouco tempo para ações de planejamento e estratégia. Um deles alegou que há “[...] falta de visão estratégica da alta administração.” (GP13, informação verbal). Outros dois justificaram expondo a ausência de tecnologias da informação. Há preocupação de gestores em tornar a área de gestão de pessoas estratégica, mas o pouco tempo destinado a isso e a ausência de sistemas de informações gerenciais que forneçam suporte na tomada de decisão e no acompanhamento das ações comprometem o desempenho desses.

Os demais desafios destacados tratam de questões comportamentais na relação com suas equipes de trabalho. Lidar com a individualidade do servidor, manter o ambiente em harmonia, atuar em equipe, conciliar opiniões e gerenciar conflitos, assim como a falta de comprometimento dos colegas de trabalho, são exemplos desses dilemas. Embora 27\% dos respondentes associem isso ao excesso de trabalho, acredita-se que o gargalo também pode ser explicado à luz da estrutura e da cultura organizacional e da trajetória educacional e profissional desses gestores.

Como explicam Borba (2012), Costin (2010) e Bergue (2014), a cultura organizacional da administração pública é permeada pelo patrimonialismo, burocracia e gerencialismo. Ora regulatório, com foco no controle, ora mais autônomo e com foco em resultados. E a tendência de os gestores assumirem uma grande carga de trabalho operacional gera pouco espaço para o seu desenvolvimento de habilidades comportamentais. Todavia, há o entendimento de que a sobrevivência organizacional está atrelada ao seu desenvolvimento permanente, assim como às pessoas que fazem parte dela (DUTRA; COMINI, 2010).

Uma alternativa pode ser o desenvolvimento gerencial em uma dinâmica mais informal, de modo a garantir esse acordo mútuo de desenvolvimento entre as pessoas e as organizações. Quanto maior a complexidade das atribuições e responsabilidades, maior deve ser o percentual de ações de desenvolvimento não formais. 
É o que Dutra e Comini (2010) explicam pelo fato de a complexidade demandar mais o uso diversificado do repertório de experiências das pessoas e suas habilidades, e menos o uso de novos repertórios, conhecimentos.

O Forgep parece estar contribuindo para isso. Mas o desenvolvimento gerencial carece de ações mais vivenciais, como fóruns EAD, grupos de trabalho, estágios, visitas, compondo um portfólio de desenvolvimento muito além dos tradicionais treinamentos.

\subsection{ENTENDIMENTOS SOBRE GESTÃO POR COMPETÊNCIAS}

No quesito "entendimentos sobre Gestão por Competências", a intenção era que os gestores descrevessem seus entendimentos sobre o tema e se estes estavam relacionados à teoria pertinente.

Diante da PNDP instituída em 2006, esperava-se que a gestão por competências fosse um assunto de domínio da maioria dos entrevistados. No entanto, isso não foi evidenciado.

Dos 45 entrevistados, 34 responderam à questão. Destes, um gestor de pessoas conceituou gestão por competências como “[...] um modelo de gestão organizacional baseado no reconhecimento, obtenção e desenvolvimento de competências essenciais (conhecimentos, habilidades e atitudes) para o alcance dos objetivos estratégicos da instituição.”(informação verbal). Este conceito é o que mais se assemelha às referências sobre o tema apresentadas anteriormente (FERNANDES, 2013; LE BOTERF, 1999; CARBONE et al., 2009; BRANDÃO, 2012). A resposta dada pelo dirigente traz o entendimento de que se trata de um modelo de gestão, relacionando competências e seus três elementos básicos à estratégia organizacional.

Embora o conceito seja abrangente, há de se considerar uma característica básica da gestão "por” competências que, conforme Fernandes (2013), a diferencia de gestão “de” competências, que é a deliberação, a institucionalização de um conjunto de competências as quais a organização deseja de seus colaboradores e utiliza sistematicamente como parâmetro para trabalhar esses profissionais.

Mas outras respostas revelam certa predominância da dimensão individual do conceito de "competências”. Treze gestores apresentaram definições nesse sentido. Cinco descrevem competência enquanto capacidade, em conjunto com habilidades, e oito ampliam o conceito a partir dos três elementos: conhecimentos, habilidades e atitudes, mas com foco na pessoa.

Isso não causa surpresa. O fato acontece diante da pseudo-similaridade de competências com qualificação. No contexto organizacional, o termo competência foi 
visto inicialmente em uma concepção individual. Os estudos de McClelland (1973) apresentam a competência implícita à pessoa, ao desempenho superior desta ao realizar uma dada tarefa ou em determinada situação. O autor caracteriza a corrente anglo-saxônica, com abordagem racionalista, em que as competências, geralmente, estão relacionadas a resultados, desempenho, talento e formação.

Mas também é comum se explicar competência no processo de ensino-aprendizagem pelo CHA, conhecimentos, habilidades e atitudes, e depois se ampliar seu escopo. Acredita-se que a influência francesa, em especial a de Philippe Perrenoud, na educação profissional e tecnológica brasileira contribuiu para isso. Seu pensamento, inclusive, serviu de base para os Parâmetros Curriculares Nacionais (PCNs) estabelecidos pelo MEC durante o governo de Fernando Henrique Cardoso.

As demais respostas trazem à tona temas correlatos à gestão por competências. Quatro se reportam ao mapeamento, duas se relacionam à qualificação, duas à gestão de talentos e cinco a desempenho. Logo, percebe-se a polissemia do termo, o que infere um conceito em construção.

Nenhum dos investigados menciona a gestão por competências entremeada por outros conceitos além do CHA, como entrega, complexidade, agregação de valor e espaço ocupacional. São conceitos contemporâneos trazidos pelo modelo de gestão por competências de Dutra (2004).

A “entrega" é o que realmente o indivíduo faz pela entidade organizacional. A "complexidade" refere-se ao nível de exigência em ações requeridas. "Agregação de valor" diz respeito à geração de resultados diferenciados diante de parâmetros estabelecidos. E o "espaço ocupacional" retrata a assunção de maiores responsabilidades em lugares físicos/administrativos variados e no mesmo nível de complexidade (DUTRA, 2004).

Então, as respostas indicam lacunas no desenvolvimento gerencial enquanto diretriz da PNDP (BRASIL, 2006). Gestores motivam e lideram equipes; por isso, o papel deles pode definir, ou não, a adoção da gestão por competências na administração pública e fazer valer a legislação vigente.

O Governo Federal, ao solicitar planos anuais de capacitação com base em competências, divulgar documentos, promover seminários e ofertar cursos, promove o tema. Contudo, para que a gestão por competências na administração pública federal se consolide de fato, são necessários investimentos financeiros para a implantação do modelo.

\subsection{PRÁTICA DA GESTÃO POR COMPETÊNCIAS}


Também se questionou se a gestão por competências estava em andamento na instituição dos gestores. Houve 32 respostas, e 13 deixaram em branco. Dos respondentes, 23 informaram que não (72\%), e 28\% dos gestores responderam sim à pergunta.

Para 22\% dos que responderam não, a justificativa está na falta de vontade da administração superior. Alguns alegaram que “[...] não há interesse institucional”, conforme GP31 (informação verbal), outros relataram que “[...] não há vontade política”, como GP07 (informação verbal), e também há respondentes que destacam resistências de superiores, o que dificulta bastante. Outros 22\% alegaram que a instituição é nova na Rede, que falta maturidade ou que houve troca da administração central e/ ou do gestor de pessoas recentemente. Outros 30\% destacam que já houve capacitação de servidores na área de gestão por competências, mas, por carência de estrutura, de servidores e de tempo, em razão do acúmulo de trabalho, as ações não avançaram. Os demais $26 \%$ apresentam outras justificativas, como:

Havia uma conversa inicial para contratarmos uma empresa para mapear as competências, mas o projeto não foi à frente. (GP40).

Há falta de conhecimento aprofundado do tema que subsidie a adoção de diretrizes. (GP11).

A equipe de psicólogas da Reitoria está formalizando um projeto focado em Gestão por Competências, porém ainda não temos planejamento para aplicação. (GP08).

Não, mas creio que foi estartada em função do atual gestor máximo que começou a levantar os caminhos, antes de indicar alguém para um cargo ou função. (GP26). (informações verbais).

No que se refere às respostas afirmativas, três gestores alegaram que estão na fase de elaboração do mapeamento de competências, constituindo comissões ou desenvolvendo o mapeamento no âmbito institucional ou individual. Outro gestor relatou que promoveram um

Encontro com os dirigentes da Instituição [...], sendo a gestão por competências o tema do evento. [...] o objetivo foi provocar a discussão e estimular a percepção dos gestores para a necessidade de adoção de um modelo de gestão mais eficiente. (GP08, informação verbal).

Outros três entrevistados salientaram que se situam em uma fase de sensibilização inicial, na qual expõem o modelo às pessoas, ou seja, "vendendo a ideia”. 
(GP12, informação verbal). Já o entrevistado GP13 explicou que estão sempre alertando as unidades de sua instituição sobre

[...] a observância à missão da instituição, ao estatuto e diretrizes institucionais, ao PDI, ao Planejamento estratégico, na definição de metas, fomentando a capacitação e avaliando sempre os seus resultados, alocando pessoal de acordo com formação, experiências e formação profissional. (informação verbal).

Em seu relato, o gestor reconhece que somente se desenvolve a gestão por competências se alinhada à gestão estratégica, que está definida em documentos como o Plano de Desenvolvimento Institucional (PDI), Regimentos e Estatutos.

\subsection{COMPETÊNCIAS GERENCIAIS EVIDENCIADAS}

Na pergunta seguinte, solicitou-se aos gestores que relacionassem uma ou mais competências gerenciais que consideravam ter. Obtiveram-se 30 respostas. Destas, apresentam-se as mais frequentes, relatadas por eles, na Tabela 1.

Tabela 1 - Competências Evidenciadas pelos Gestores de Pessoas

\begin{tabular}{ll}
\hline Competência & Freq. da Comp. (\%) \\
\hline Comunicação & 30 \\
\hline Liderança & 26 \\
\hline Gestão de conflitos & 23 \\
\hline Organização & 17 \\
\hline Planejamento & 17 \\
\hline Comprometimento & 10 \\
\hline Iniciativa & 10 \\
\hline Conhecimento técnico & 10 \\
\hline Visão estratégica & 6 \\
\hline Cria ferramentas de controle & 6 \\
\hline Transmite confiança & 6 \\
\hline Avaliação de resultados & 6 \\
\hline Visão sistêmica dos processos e da IES & 6 \\
\hline Paciência - tranquilidade & 6 \\
\hline Fone: os autar & \\
\hline
\end{tabular}

Fonte: os autores.

Observa-se que as competências “comunicação e liderança” foram as mais citadas tanto no quesito competências dominantes quanto nas passíveis de desenvolvimento. As respostam demonstram que as competências sociais predominam (FLEURY; FLEURY, 2008). 
Por um lado, isso infere a (in)experiência gerencial, seja por ter pouco ou muito tempo no exercício da função, seja como as pessoas foram educadas para trabalhar. Muitas organizações ainda mantêm práticas tradicionais de gestão de pessoas que têm sua gênese na administração científica, na "busca da pessoa certa para o lugar certo, e estão ancoradas no controle” como referencial na relação pessoas-organização, em que o colaborador tem um papel passivo, já que é objeto de controle (DUTRA; COMINI, 2010).

Barlett e Ghoshal (apud KILIMNIK; SANT’ANA, 2006) identificam categorias de competências gerenciais comumente requeridas: características de personalidade, atributos de conhecimentos e habilidades especializadas. Esses autores ajudam a se compreender que os perfis atitudinais gerenciais com traços como integrador, flexível, perceptivo e exigente têm habilidades para desenvolver pessoas e relações. Nesse sentido, gerentes em um nível intermediário delegam, desenvolvem e “dão poder”, pois têm habilidades para desenvolver relações de equipe e reconciliar diferenças.

Mas em um nível de alta direção, estratégico, seus traços visionários, perspicazes e inspiradores culminam com habilidades para motivar e inspirar confiança e crença na instituição (BARLETT; GHOSHAL apud KILIMNIK; SANT’ANA, 2006).

\subsection{COMPETÊNCIAS GERENCIAIS DESEJADAS}

Ao final, buscou-se conhecer quais competências gerenciais eram desejadas pelos gestores entrevistados ou as quais eles entendiam que deveriam ser aprimoradas. Organização do tempo, comunicação, motivação e liderança foram as mais citadas. Logo, percebe-se que a maior demanda está no componente da competência que se refere à "habilidade”, que é a “[...] capacidade de transformação do conhecimento em ação”, conforme Bergue (2014, p. 263). As respostas demonstram que os gestores detêm o conhecimento na área. Apenas dois fazem menção à necessidade de mais domínio da legislação e de tempo para estudá-la.

A organização do tempo está relacionada ao saber diferenciar o urgente do importante. GP34 (informação verbal), por exemplo, precisa “[...] aprender a organizar melhor o tempo para evitar o excesso de atividades.” Para GP7 (informação verbal), o gerenciamento do tempo é prioritário, “[...] em função da crescente demanda de trabalho, desproporcional ao aumento da força de trabalho na Instituição. É aprender gerenciar o tempo, para manter um alto nível de produtividade.” (informação verbal).

A liderança, por sua vez, aparece nos relatos como competência já adquirida, mas passível de ser aprimorada. GP13 enfatiza a liderança situacional. Para ele, a 
Atuação como Coaching [...] as pessoas são o grande desafio dos gestores. E esse desafio cresce a cada dia. Ter competências voltadas para orientação das equipes e capacidade de desenvolver o melhor das pessoas é o caminho para o sucesso do gestor. É preciso estar consciente de que a gestão de pessoas guarda um modelo de gestor para cada pessoa. (informação verbal).

Outro gestor destaca que é preciso “[...] aprimorar a capacidade em levar o grupo a aceitar ideias e trabalhar para atingir os objetivos.”(GP29 informação verbal). E outra deseja “[...] liderar para poder ser líder, não chefe.”(GP22) (informação verbal).

Na resposta “comunicação”, um dos gestores argumenta que "gostaria de ser comedido no falar o que pensa.”(GP14 informação verbal). Para outro, desenvolver a comunicação ajudaria para “[...] expressar melhor as minhas ideias e conseguir convencer aos que estão em minha volta.”(GP45 informação verbal). Já o gestor GP33 acrescenta a oratória. Para ele é para “[...] melhorar a parte política, articulada, que o gestor deve ter com a comunidade externa da Instituição.” (informação verbal).

A motivação, enquanto competência a ser desejada ou desenvolvida, infere respostas relacionadas a estímulos aos membros da equipe a se motivarem. Um dos gestores alega que "Por atuar na Administração Pública, aonde as coisas não acontecem na celeridade que se gostaria, fica difícil manter os servidores motivados.” Outros destacam a importância da motivação ao longo da carreira, como afirma GP45: “O Instituto possui servidores próximos de se aposentar que estão desmotivados.” (informações verbais).

\section{CONCLUSÃO}

Neste estudo, a intenção foi mapear as competências gerenciais e demais informações a partir dos relatos de gestores de pessoas - Forgep - Conif. As respostas revelam uma conta que não fecha nos desafios cotidianos desses profissionais: as demandas de trabalho aumentam e os servidores são cada vez mais escassos.

Seus entendimentos sobre gestão por competências não estão claros se comparados à literatura pertinente. Há lacunas no desenvolvimento gerencial nesse campo se considerarmos o tempo de implantação da PNDP (BRASIL, 2006).

Investimentos do governo na socialização dos saberes e práticas no âmbito da gestão por competências são urgentes, e os gestores são sujeitos significativos na sensibilização para esse modelo de gestão de pessoas.

Conforme 72\% dos respondentes, a prática da gestão por competências não acontece em suas instituições. Um caminho talvez seja a criação de uma rubrica or- 
çamentária específica para o desenvolvimento da gestão por competências no setor público, fomentando, especialmente, o desenvolvimento gerencial.

Observa-se que as competências sociais "comunicação e liderança" predominam tanto no quesito competências dominantes quanto nas passíveis de desenvolvimento.

Espera-se que este estudo contribua para ações de Governo mais efetivas, e sugerem-se pesquisas futuras no âmbito das competências gerenciais desenvolvidas e do resultado do desenvolvimento destas para as organizações. Nem sempre o desenvolvimento profissional caminha lado a lado com o desenvolvimento organizacional. É essencial conceber o efetivo TD\&E de gestores de pessoas, essenciais no desenvolvimento da gestão por competências na prática.

\section{REFERÊNCIAS}

ANTONELLO, C. S. Alternativas de articulação entre programas de formação gerencial e as práticas de trabalho: uma contribuição no desenvolvimento de competências. 2004. Tese (Doutorado em Administração)-Universidade Federal do Rio Grande do Sul, Porto Alegre, 2004.

ANTONELLO, C. S. et al. (Org.). Gestão de pessoas: bases teóricas e experiências no setor público. Brasília: ENAP, 2010.

BARDIN, L. Análise de conteúdo. Tradução Luís Antero Reto e Augusto Pinheiro. Lisboa: Edições 70, 2009.

BERGUE, S. T. Gestão estratégica de pessoas no setor público. São Paulo: Atlas, 2014.

BORGES-ANDRADE, J. E.; ABBAD, G. S.; MOURÃO, L. Treinamento, desenvolvimento e educação em organizações e trabalho: fundamentos para a gestão de pessoas. Porto Alegre: Artmed, 2006.

BRANDÃO, H. P. et al. Desenvolvimento e Estrutura Interna de uma Escala de Competências Gerenciais. Psicologia: Teoria e Pesquisa, v. 26, n. 1, p. 171-182, jan./ mar. 2010.

BRANDÃO, H. P. et al. Relationships between learning, context and competency: a multilevel study. BAR, Braz. Adm. Rev., Rio de Janeiro, v. 9, i. 1, mar. 2012. Disponível em: <http://dx.doi.org/10.1590/S1807-76922012000100002>. Acesso em: 17 mar. 2015. 
BRANDÃO, H. P. Mapeamento de competências: métodos, técnicas e aplicações em gestão de pessoas. São Paulo: Atlas, 2012.

BRASIL. Decreto n. 5.707, de 23 de fevereiro de 2006. Institui a Política e as Diretrizes para o Desenvolvimento de Pessoal da administração pública federal direta, autárquica e fundacional, e regulamenta dispositivos da Lei n. 8.112, de 11 de dezembro de 1990. Diário Oficial da União, Brasília, DF, 23 nov. 2006. Disponível em: <http://www.planalto.gov.br/ccivil_03/_Ato2004-2006/2006/Decreto/D5707. htm>. Acesso em: 30 nov. 2013.

BRASIL. Ministério do Planejamento, Orçamento e Gestão. Secretaria de Gestão Pública. Guia de Mapeamento e Avaliação de Competências para a Administração Pública - Poder Executivo. Brasília, DF, 2013.

BRASIL. Portaria n. 27, de 15 de janeiro de 2014. Institui o Plano Nacional de Desenvolvimento Profissional dos servidores integrantes do Plano de Carreira dos Cargos Técnico-Administrativos em Educação, no âmbito das Instituições Federais de Ensino vinculadas ao Ministério da Educação. Diário Oficial da União, Brasília, DF, 16 jan. 2014.

BRUNO-FARIA, M. F.; BRANDÃO, H. P. Competências relevantes a profissionais da área de T\&D de uma organização pública do Distrito Federal. Revista de Administração Contemporânea, v. 7, n. 3, p. 35-56, jul./set. 2003.

CARBONE, P. P. et al. Gestão por competências e gestão do conhecimento. 3. ed. Rio de Janeiro: Fundação Getúlio Vargas, 2009.

CARDOSO, R. L. et al. International competence and knowledge studies and attitudes of the Brazilian Management accountant: analyses and reflections. BBR Brazilian Business Review, Vitória, v. 7, i. 3, p. 87-107, Sept./Dec. 2010.

CONSELHO NACIONAL DAS INSTITUIÇÕES DA REDE FEDERAL DE EDUCAÇÃO PROFISSIONAL, CIENTÍFICA E TECNOLÓGICA. Disponível em: <www.conif.org.br>. Acesso em: 26 out. 2013.

COSTIN, C. Administração pública. Rio de Janeiro: Elsevier, 2010.

DONADÃO, D. Desenvolvimento Gerencial (DG). In: BOOG, G.; BOOG, M. (Coord.). Manual de Treinamento e Desenvolvimento: processos e operações. 6. ed. São Paulo: Pearson Education do Brasil, 2013. v. 2. 
DUTRA, J. S. Competências: Conceitos e Instrumentos para a Gestão de Pessoas na Empresa Moderna. São Paulo: Atlas, 2004.

DUTRA, J. S.; COMINI, G. M.. Competência como base para a gestão estratégica de pessoas. In: EBOLI, M. et al. Educação Corporativa: fundamentos, evolução e implantação de projetos. São Paulo: Atlas, 2010.

ESCOLA NACIONAL DE ADMINISTRAÇÃO PÚBLICA. Papel do gerente na gestão do desempenho de equipe. Brasília, DF: ENAP, 2012.

FERNANDES, B. R. Gestão estratégica de pessoas com foco em competências. Rio de Janeiro: Elsevier, 2013.

FLEURY, A.; FLEURY, M. T. L. Estratégias empresariais e formação de competências: um quebra-cabeça caleidoscópico da indústria brasileira. São Paulo: Atlas, 2008.

FLEURY, M. T.; FISCHER, R. M. "Relações de trabalho e políticas de gestão: uma história das questões atuais". Revista de Administração da USP, v. 27, n. 4, out./ dez. 1992.

HELMANN, G. J. O Observatório Regional como ferramenta de gestão nos Institutos Federais de Educação, Ciência e Tecnologia: o caso do Instituto Federal do Paraná. Revista Brasileira de Desenvolvimento Regional, Blumenau, v. 2, n. 2, p. 153-184, 2014.

KILIMNIK, Z. M.; SANT'ANA, A. S. Modernidade organizacional, políticas de gestão de pessoas e competências profissionais. In: BORGES-ANDRADE, J. E.; ABBAD, G. S.; MOURÃO, L. Treinamento, desenvolvimento e educação em organizações e trabalho: fundamentos para a gestão de pessoas. Porto Alegre: Artmed, 2006.

LE BOTERF, G. Compétence et navigation professionnelle. Paris: Éditions d'Organisation, 1999.

LE BOTERF, G. Construire les competences individuelle set collectives. Paris: Éditions d'Organisation, 2002.

MAXIMIANO, A. C. A. Introdução à Administração. 6. ed. São Paulo: Atlas, 2004. 
McCLELLAND, David C. Testing for Competence rather than Intelligence. American Psychologist, p. 1-14, jan. 1973.

MELLO, S. P. T. (Org.). Administração pública contemporânea: questões para o debate. Pelotas: Editora da UFPel, 2012.

MELLO, S. P. T. Competências requeridas - competências adquiridas: o curso superior de Tecnologia em Sistemas de Telecomunicações do CEFET Pelotas - RS no contexto das mudanças advindas da reforma da educação profissional. 2007. Tese (Doutorado em Educação)-Universidade Federal do Rio Grande do Sul, Porto Alegre, 2007.

PALUDO, A. Administração pública: questões. Rio de Janeiro: Elsevier, 2013.

TRIBUNAL DE CONTAS DA UNIÃO. Disponível em: < http://portal2.tcu.gov.br/ portal/page/portal/TCU/imprensa/noticias/noticias_arquivos/022.577-2012-2\%20 governan\%C3\%A7a\%20de\%20pessoal.pdf>. Acesso em: 10 dez. 2013.

VERGARA, S. C. Métodos de pesquisa em Administração. São Paulo: Atlas, 2006.

ZARIFIAN, P. Objectif compétence. Pour une nouvelle logique. 1999.

Como citar este artigo:

\section{ABNT}

MELLO, P. T. Simone; MELO, Pedro Antônio de; MELLO FILHO, Raul Teixeira. Competências gerenciais evidenciadas e desejadas dos integrantes do fórum de gestão de pessoas da rede federal de educação profissional, ciência e tecnológica.

RACE: Revista de Administração, Contabilidade e Economia, Joaçaba: Ed. Unoesc, v. 15, n. 1, p. 349-374, jan./abr. 2016. Disponível em: <http://editora.unoesc.edu.br/ index.php/race>. Acesso em: dia/mês/ano.

\footnotetext{
APA

Mello, P. T. S., Melo, P. A. de, \& Mello Filho, R. T. (2016). Competências gerenciais evidenciadas e desejadas dos integrantes do fórum de gestão de pessoas da rede federal de educação profissional, ciência e tecnológica. RACE: Revista de Administração, Contabilidade e Economia, 15(1), 349-374. Recuperado em dia/mês/ano, de http://editora.unoesc.edu.br/index.php/race
} 